\title{
Editorial
}

\section{Nanomaterials for Green Science and Environmental Applications}

\author{
Ki-Joon Jeon, ${ }^{1}$ Wei-Chun Chin, ${ }^{2}$ Jong-Yeop Kim, ${ }^{3}$ and Cheol-Min Park ${ }^{4}$ \\ ${ }^{1}$ Department of Environmental Engineering, Inha University, Incheon 402-751, Republic of Korea \\ ${ }^{2}$ Bio-Engineering Department, University of California, Merced, 5200 N. Lake Road, Merced, CA 95343, USA \\ ${ }^{3}$ Department of Environmental Engineering, Florida Gulf Coast University, Fort Myers, FL 33965-6565, USA \\ ${ }^{4}$ School of Materials Science and Engineering, Kumoh National Institute of Technology, Gyeongbuk 730-701, Republic of Korea
}

Correspondence should be addressed to Ki-Joon Jeon; kjjeon@inha.ac.kr

Received 28 April 2015; Accepted 28 April 2015

Copyright (C) $2015 \mathrm{Ki}$-Joon Jeon et al. This is an open access article distributed under the Creative Commons Attribution License, which permits unrestricted use, distribution, and reproduction in any medium, provided the original work is properly cited.

Recently, wide ranges of new functional nanomaterials have been developed toward advancements in energy and environmental related issues. The motivation of this special issue is to deliver the timely and emerging research activities on the synthesis, structural manipulation, characterization, surface modification, processing, and integration of nanomaterials for green energy and environmental applications. This special issue provides an in-depth exchange of research ideas from various researchers, engineers, and scientists, in the domain of interest around the world and design research activities on above topics. The energy related nanomaterials for solar cells, fuel cells, supercapacitors, lithium ion batteries, hydrogen storage systems, and thermoelectric and renewable energy systems were discussed. Further environmental remediation systems such as detection and remediation of different contaminants/pollutants, catalysts for noxious and toxic gases, sensor electrodes, immobilization matrices and selective gas sensing probes, and waste/biomass to energy were also included.

This special issue contains collection of papers on synthesis of nanomaterials for energy and environmental applications: the special issue contains articles related to photocatalyst, like 1D titanate nanotube for photocatalytic application and the relation between performance of titanate nanotubes with structural and chemical composite. One of the articles describes the photoelectron catalysis degradation of landfill leachate using $\mathrm{Cu} / \mathrm{N}$ codoped $\mathrm{TiO}_{2}$. The special issue also covers article related to synthesis and characterization of bio-oil. In an article, the authors describe the method of synthesizing bio-oil from Quercus variabilis tree. The authors also explored bio-oil's performance with various catalysts along with chemical changes. Another article related to biooil also describes synthesis of bio-oil from waste pepper stems by fast pyrolysis method. The special issue also covers nanomaterial for environmental pollution and pest control. In this section, biosynthesized silver nanoparticles are explored for controlling plant pathogenic fungi. The authors in their experiment exposed a land snail to synthesized silver particles and observed reduction in the activity and viability of land snail and surrounding fungus in the soil. Their study also opens new avenue to use the snail as bioindicator organism of environmental pollutions. Last but not least on pest control application, an article describes synthesis of silver nanoparticles through processing plant leaf extract method and the authors report the effect of synthesized Ag nanoparticles in controlling the fruit fly pest.

Overall, we hope that readers of this special issue will find updated articles about synthesis, optimization, and characterization of various nanostructured materials that finds emerging application in energy and environmental applications.

Ki-Joon Jeon

Wei-Chun Chin

Jong-Yeop Kim

Cheol-Min Park 

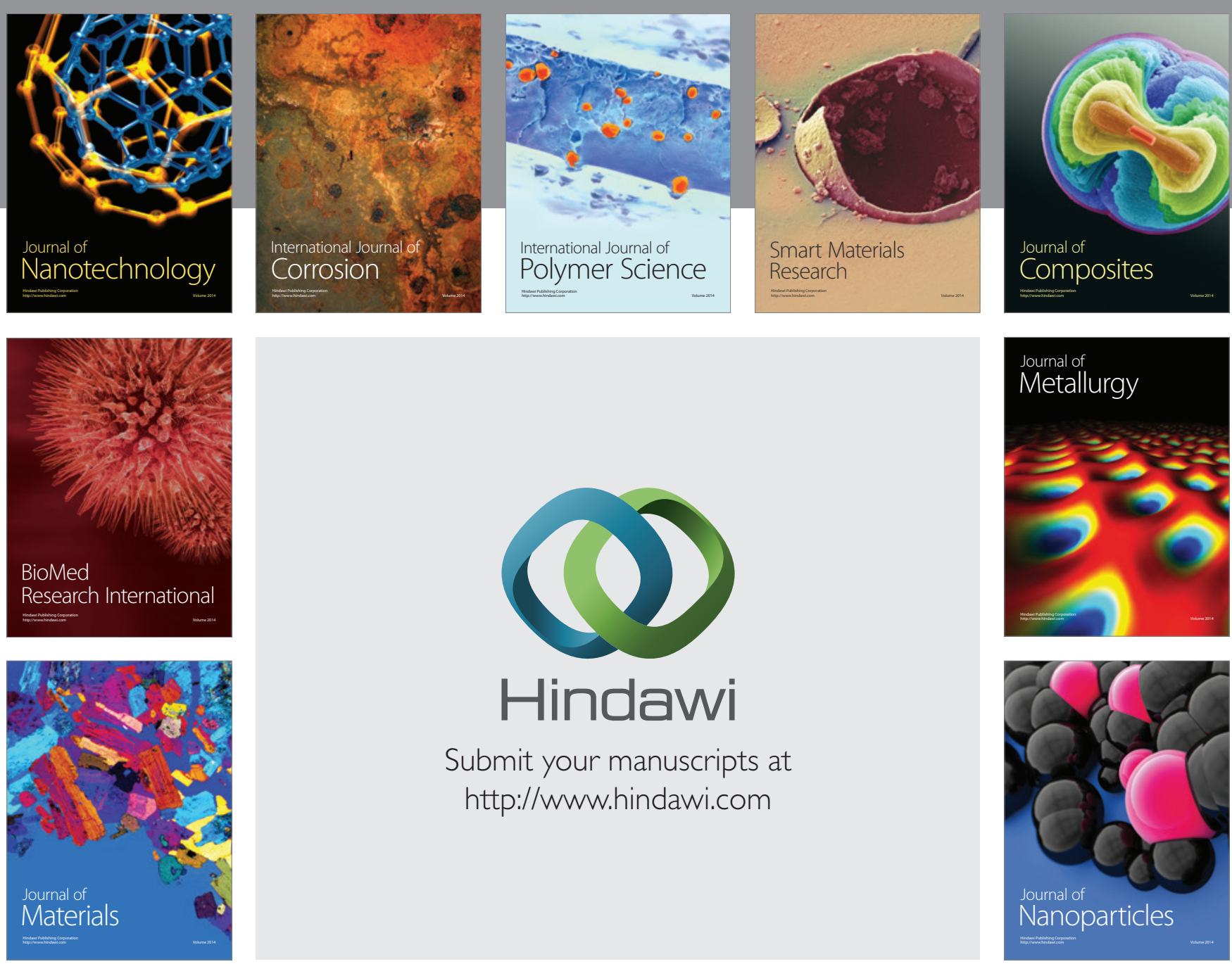

Submit your manuscripts at http://www.hindawi.com
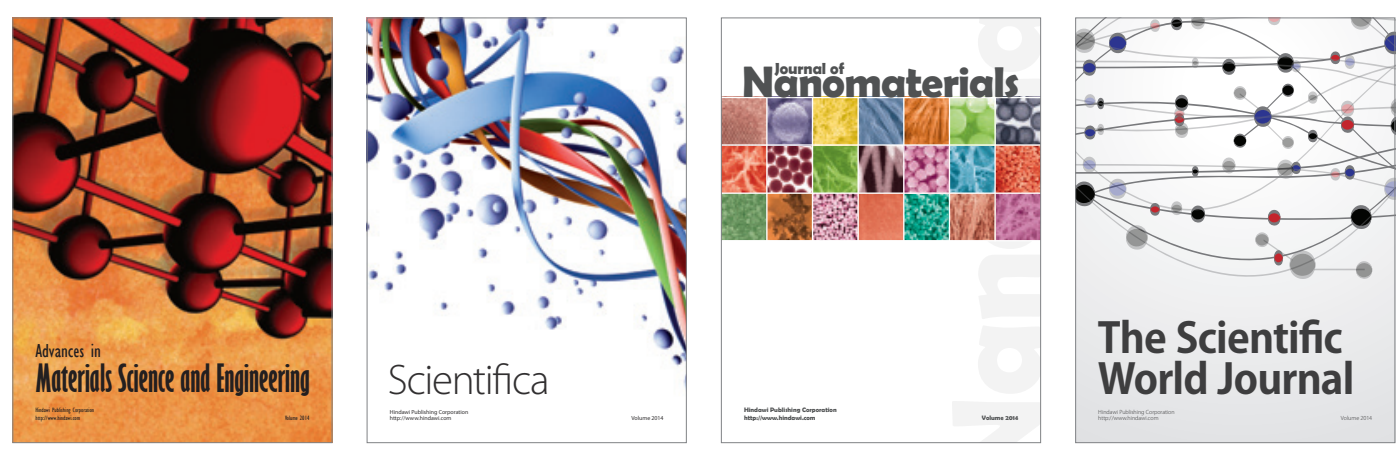

\section{The Scientific World Journal}
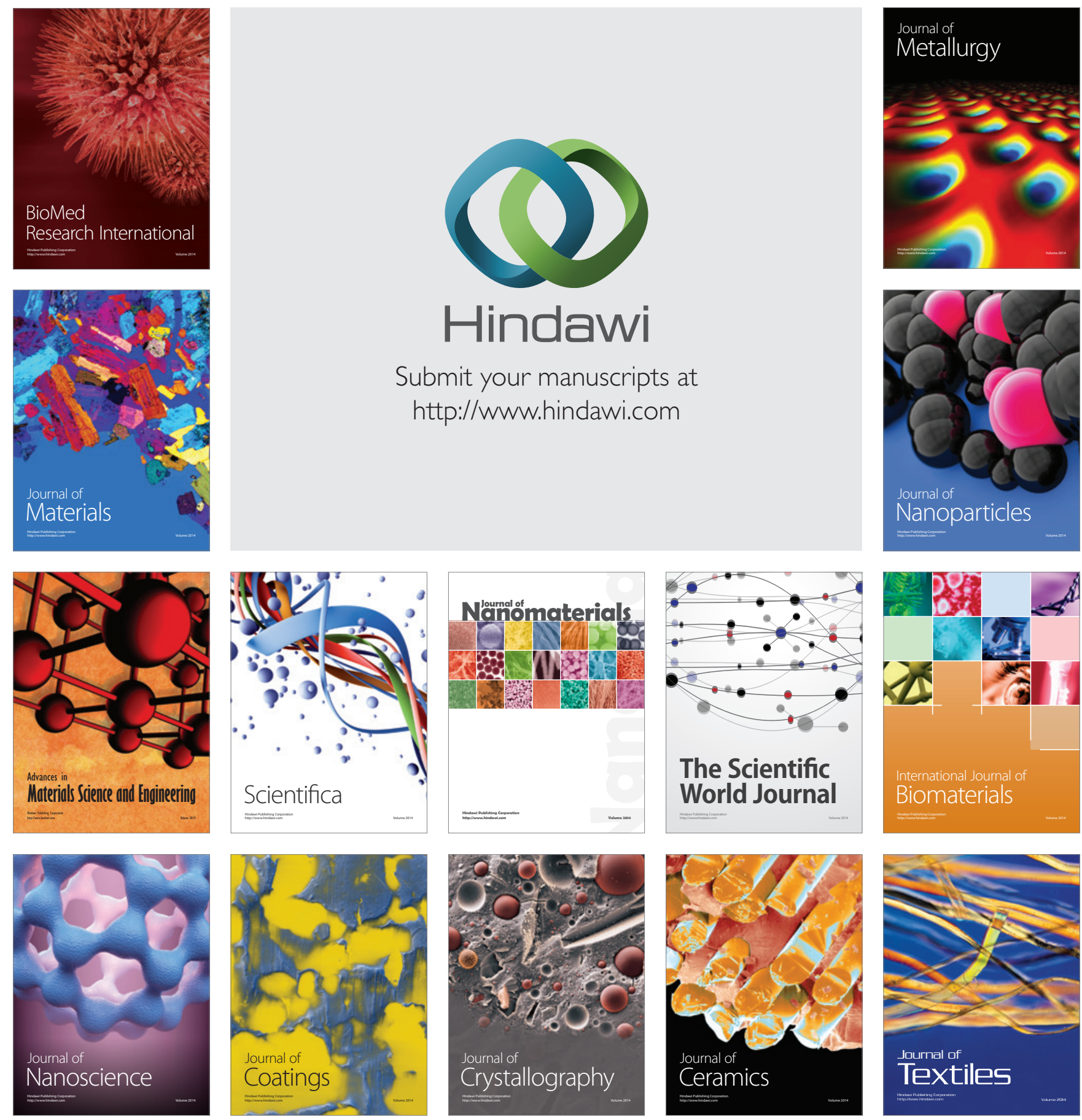